\title{
Educação em Tempos Neoliberais: ferramentas para leitura da concepção de Educação Superior do Banco Mundial (Relatório de Novembro de 2017)
}

\author{
Education in Neoliberal Times: notes for reading the World Bank's \\ concept of Higher Education (November 2017 Report)
}

1 Eduardo Cristiano Hass da Silva eduardohass.he@gmail.com

1 Professor da Faculdade de Engenharia, Letras e Ciências Sociais do Seridó (FELCS) da Universidade Federal do Rio Grande do Norte (UFRN). Doutor em Educação pela Universidade do Vale do Rio dos Sinos. Mestre, graduado (licenciatura e bacharelado) em História pela Pontifícia Universidade Católica do Rio Grande do Sul.

\section{Resumo}

O presente texto tem o objetivo de oferecer um gradiente de leitura que permita compreender, analisar e criticar o relatório 'Um Ajuste Justo: Análise da Eficiência e Equidade do Gasto Público no Brasil', publicado no mês de novembro de 2017, pelo Grupo Banco Mundial. Acreditando que o relatório se encontra fortemente permeado por uma lógica neoliberal, o artigo toma a noção de neoliberalismo como guia para a leitura do documento. São apresentados conceitos de autores como Ball (2004), Bauman e Bordoni (2016), Dardot e Laval (2016), Veiga-Neto (2002), dentre outros. O texto encontra-se estruturado em cinco partes: "Neoliberalismo: conhecer para combater"; "Estado em tempos neoliberais"; "O sujeito neoliberal", "Educação em Tempos Neoliberais" e "Alguns apontamentos". Nesse último tópico, são apresentadas algumas observações finais que auxiliam a compreender o relatório como parte de uma rede de interesses pautada pelo capital, situada dentro do modelo neoliberal, que entende os as aplicações em educação não como investimentos, mas como gastos.

\section{Palavras-chave:}

Neoliberalismo. Educação neoliberal. Crise na educação.

\section{Abstract}

This text has the objective of offering a reading gradient to understand, analyze and criticize the report " $A$ fair adjustment: An analysis of the efficiency and equity of spending public in Brazil," published in November 2017 by the World Bank Group. Arguing that the report is strongly permeated by a neoliberal logic, the article uses the notion of neoliberalism as a guide for reading the document. Authors concepts are presented as Ball (2004), and Bauman Bordoni (2016), and Dardot Laval (2016), VeigaNeto (2002), among others. The text is structured in five parts: "Neoliberalism: to know to fight"; "State in neoliberal times"; "The neoliberal subject", "Education in Neoliberal Times" and "Some notes". In this last topic we present some concluding observations that help to understand the report as part of a network of interests guided by capital, located within the neoliberal model, which understands investments in education not as investments, but as expenses.

\section{Keywords:}

Neoliberalism. Neoliberal education. Crisis in education.

\section{Como você deve citar?}

SILVA, Eduardo Cristiano Hass da. Educação em Tempos Neoliberais: ferramentas para leitura da concepção de Educação Superior do Banco Mundial (Relatório de Novembro de 2017). Cadernos UniFOA, Volta Redonda (RJ), v. 16, n. 46, p. 1-11, ago, 2021. 
Educação em Tempos Neoliberais: ferramentas para leitura da concepção de Educação Superior do Banco Mundial (Relatório de Novembro de 2017)

\title{
1 INTRODUÇÃO
}

No mês de novembro de 2017, foi publicado, pelo Grupo Banco Mundial, o Relatório 'Um Ajuste Justo: Análise da Eficiência e Equidade do Gasto Público no Brasil'. Composto por 160 páginas, o relatório discorre sobre a Revisão das Despesas Públicas no país. Dentre os pontos abordados, estão os 'Desafios para a Sustentabilidade Fiscal no Brasil', 'Peso da Folha do Funcionalismo Público', 'Compras Públicas: Planejamento e Estratégias de Licitações para Eficiência Fiscal', 'Previdência Social: Uma Conta Impagável', 'Programas de Apoio ao Mercado do Trabalho e Assistência Social: Integrar para Melhorar', 'Saúde: Alternativas para Oferecer Mais e Melhores Serviços', 'Gastar Mais ou Melhor? Eficiência e Equidade da Educação Pública' e 'Políticas de Apoio ao Setor Privado dão Retorno para a Sociedade?'. Dentro do capítulo 'Gastar Mais ou Melhor? Eficiência e Equidade da Educação Pública', o tópico 'Eficiência dos gastos com educação' encontra-se dividido em uma sessão para o ensino fundamental e médio e outra para o ensino superior. 0 que o relatório traz sobre os gastos com educação superior no país? Após afirmar que a maioria dos brasileiros está matriculada no ensino superior privado, o relatório apresenta

\begin{abstract}
Em média, um estudante em universidades públicas no Brasil custa de duas a três vezes mais que estudantes em universidades privadas. Entre 2013 e 2015, o custo médio anual por estudante em universidades privadas sem e com fins lucrativos foi de aproximadamente R\$ 12.600 e R\$14.850, respectivamente [...]. Em universidades federais, a média foi de $\mathrm{R} \$ \mathbf{4 0 . 9 0 0}$. Universidades públicas estaduais custam menos do que as federais, mas ainda são muito mais caras do que as privadas, custando aproximadamente de R\$32.200. 0 custo por aluno dos institutos federais, a maior parte fundada desde 2008, é de aproximadamente R\$ 27.850 . (RELATÓRIO DO BANCO MUNDIAL, 2017, p. 131 - Grifo no original).
\end{abstract}

Como pode-se observar, o relatório entende os investimentos em ensino superior público não como investimentos, mas como custos. Além disso, o documento destaca que os alunos desse sistema de ensino custam mais do que os alunos da rede privada. Depois de apresentar esse diagnóstico, o relatório ainda destaca: "as universidades privadas Brasileiras tendem a ser mais custo eficientes do que as públicas" (RELATÓRIO DO BANCO MUNDIAL, 2017, p. 134).

Quais motivações levam o relatório apresentado por essa instituição a entender o ensino público superior como custo, e não investimento? Por que o relatório propõe, de forma indireta, que o Estado deixe de ser o responsável por oferecer o ensino público de qualidade, passando este a ser responsabilidades dos próprios sujeitos? 0 que sustenta esse caráter de privatização do ensino? Acredito que a mesma resposta possa ser apresentada aos três questionamentos: o relatório é pautado por uma lógica neoliberal.

Considerando essas colocações iniciais, o presente texto não tem a preocupação de analisar o relatório citado, mas sim, oferecer um gradiente de leitura, um referencial teórico que permita, a partir dele, a compreensão do referido documento. Não defendo que o neoliberalismo seja o único conceito potente para pensar o relatório, mas será o adotado neste artigo.

Sendo assim, o texto encontra-se estruturado em cinco partes. Na primeira, intitulada de "Neoliberalismo: conhecer para combater", proponho algumas aproximações para compreender o neoliberalismo como uma forma de mutação do capitalismo, na qual o trabalhador torna-se empresário de si mesmo. Além disso, destaco a importância de compreender essa forma de vida para poder combatê-la. No tópico "Estado em tempos neoliberais", proponho algumas chaves de leitura para compreender como o sistema neoliberal interfere diretamente no Estado e nas suas responsabilidades. Na terceira parte, "O sujeito neoliberal", apresento como o neoliberalismo age diretamente dos sujeitos. Após as colocações de caráter mais geral, preocupo-me especificamente com a forma como o neoliberalismo interfere na educação, a partir do tópico "Educação em Tempos Neoliberais", apresentando um levantamento de conceitos e autores que têm se preocupado com a relação entre neoliberalismo e educação, sendo eles: "Currículo, Tempo e Espaço: Individualismo e Transitoriedade" (VEIGA-NETO, 2002); "Aprendizagem ao 
longo da vida" (LIMA, 2010); e "Dispositivo de Aprendizagem" (SIMONS; MASSCHELEIN, 2013). Para finalizar, proponho algumas observações que articulam as ideias aqui apresentadas.

\section{NEOLIBERALISMO: CONHECER PARA COMBATER}

Tomando o neoliberalismo como conceito para pensar o Relatório do Banco Mundial e suas colocações sobre a Educação Superior Pública, penso ser de grande importância apresentar o que aqui se entende por neoliberalismo, bem como discutir possíveis formas de resistência. Para Laval e Dardot (s.n.), não há resistência ao neoliberalismo sem se conhecer como ele opera, o que mostra a relevância deste estudo que atenta especificamente para a interface entre neoliberalismo e educação. Ao destacar a importância de tomarmos conhecimento sobre o neoliberalismo, os autores afirmam:

[...] creemos conocer el neoliberalismo cuando en realidad no sabemos exactamente lo que es ni de dónde viene. Resistir eficazmente, luchar contra una situación intolerable, no sólo requiere una buena organización y una estrategia eficaz, sino también, y sobre todo, una inteligencia colectiva de la situación, que puede lograrse a través de la discusión de trabajos teóricos de profundidad en y por los movimientos (s.n.).

Considerando a necessidade de conhecer para combater, inicio destacando que o neoliberalismo pode ser entendido como uma forma de mutação do capitalismo que converte o trabalhador em empresário de si mesmo. Enquanto no capitalismo tradicional a burguesia explora o proletário, no neoliberalismo, o trabalhador passa a se autoexplorar, tornando-se patrão e, ao mesmo tempo, escravo de si mesmo.

Laval e Dardot (s.n.) entendem o neoliberalismo não apenas como um modo econômico, mas como uma forma de viver que fabrica seus próprios sujeitos, marcados pela individualização extrema. Para eles, o neoliberalismo difere do liberalismo clássico. Enquanto o liberalismo é característico no século XVIII, como mercado abandonado ao seu "curso natural" (Adam Smith), o neoliberalismo estende a lógica do mercado, convertendo-se em "un conjunto de prácticas y de normas construidas política, institucional y jurídicamente" (LAVAL; DARDOT, s.n.).

Assim como Laval e Dardot (s.n.), Bauman e Bordoni (2016) também apontam as diferenças entre liberalismo clássico e neoliberalismo. Para eles, o primeiro pode ser entendido como um modelo puramente de mercado, marcado pela iniciativa privada e pela livre concorrência, enquanto o segundo é marcado pelos cidadãos empreendedores, em um contexto no qual as atividades que o Estado garantia em favor do público passam a ser submetida à lógica do cálculo econômico, abrindo espaço para um intenso processo de privatização.

Entendendo o neoliberalismo como uma forma de vida e como um conjunto de práticas e normas, Laval e Dardot (s.n.) mostram como ele está presente tanto na política de âmbito macro quanto micro. Considerando o plano micro, o neoliberalismo converte-se em uma forma de existência, influenciando diretamente na conduta dos sujeitos. Para os autores, esse governo das condutas pode ser potencialmente estudado a partir de alguns conceitos do filósofo Foucault.

Uma possibilidade de pensar o neoliberalismo se dá através do que Bauman e Bordoni (2016, p.9) chamam de 'Estado de Crise'. Para os autores, a ideia de crise tem muitas aplicações, sendo, dentre elas, "[...] usada para justificar dificuldades financeiras, aumento de preços, queda na demanda, falta de liquidez, imposição de novas taxas ou tudo isso junto". Especificamente sobre a crise econômica, os autores afirmam que: 
Educação em Tempos Neoliberais: ferramentas para leitura da concepção de Educação Superior do Banco Mundial (Relatório de Novembro de 2017)

crise econômica é, segundo os dicionários, uma fase de recessão caracterizada por falta de investimentos, diminuição de produção, aumento do desemprego, um termo que tem significado geral de circunstâncias desfavoráveis com frequência ligadas à economia (BAUMAN; BORDONI, 2016, p. 9).

A partir do conceito apresentado pelos autores, pode-se aferir que, em diferentes momentos históricos, vivenciamos diferentes formas de crise, como a chamada 'Crise de 1929' e a crise dos anos 1960/1970. Para Bauman e Bordoni (2016), a crise mais séria da modernidade teria sido a de 1929, mas que se diferencia muito da crise que vivenciamos hoje.

Mas que crise é essa da qual falamos na atualidade? Bauman e Bordoni (2016) destacam que, enquanto em 1929 vivenciava-se uma crise industrial, hoje vivemos em uma crise financeira. Os autores destacam que passamos por um processo de colonização econômica e cultural, a partir da invasão dos mercados mundiais por grandes corporações multinacionais, sendo a crise "(...) caracterizada pela combinação simultânea de uma aposta econômica no âmbito internacional (as causas) e as medidas tomadas para lidar com isso (os efeitos)" (BAUMAN; BORDONI, 2016, p. 11).

Como consequências da crise, os autores apontam o aumento dos preços para compensar a diminuição de vendas, que, por sua vez, fazem os preços de mercado dobrarem, aumentando os valores dos bens de consumo. Além disso, apontam ainda a 'Síndrome de Titanic' (euforia contagiosa enquanto o país está afundando); o 'efeito eco' (gastar baseado na renda do ano anterior); os suicídios e a inflação. Bauman e Bordoni (2016, p. 18) destacam que, em momentos de crise, o Estado passa a ser incapaz de cumprir suas promessas, fazendo diminuir a fé nele depositada.

Na percepção popular, ajudada e encorajada pelo coro de uma parcela crescente do público instruído e formador de opinião, o Estado foi rebaixado da posição de motor mais poderoso do bem-estar universal àquela de obstáculo mais odioso; pérfido e prejudicial.

Como pode-se observar no trecho citado, em tempos de crise, o Estado é rebaixado do lugar de motor do bem-estar universal para um obstáculo odioso, pérfido e prejudicial. Como se dá esse processo de transição? 0 que torna o estado um vilão? Acredito que pensar o Estado em tempos neoliberais permita algumas aproximações às possíveis respostas desses questionamentos.

\section{ESTADO EM TEMPOS NEOLIBERAIS}

Considerando que o Relatório apresenta o ensino superior como 'custo' para o Estado e, entendendo essa colocação como uma aproximação à política neoliberal, proponho discutir algumas das transformações do Estado em tempos neoliberais.

De acordo com Bauman e Bordoni (2016), o Estado não dispõe mais dos meios e recursos para executar suas tarefas, uma vez que não é mais o mesmo Estado de cem anos atrás. Enquanto o Estado moderno era marcado pela hierarquia e pela existência de instituições disciplinares (família, escola, fábrica, hospital, quartel, prisão), o Estado, em tempos neoliberais, situa-se em rede (formando uma heterarquia, na qual os sujeitos exercem poder em diferente intensidade, de acordo com o local ocupado na rede), sendo gestado a partir da lógica empresarial. Para entender a configuração do Estado em tempos neoliberais, acredito ser de suma importância analisar as diferentes características apresentadas.

Para pensar o Estado configurado a partir da noção de redes, utilizo-me de Stephen Ball (2014). Segundo o autor, a ideia de rede permite entender os fluxos e mobilidades estritamente ligados à globalização. Para ele, a rede pode ser pensada como um dispositivo analítico dentro da reorientação das formas distantes e fugazes de interação social. No caso específico das redes políticas, podemos en- 
tendê-las como um novo tipo social, que envolve as relações sociais, fluxos e movimentos de diferentes comunidades políticas.

Enquanto, no Estado moderno, os sujeitos eram organizados de forma hierárquica, ocupando posições específicas, a organização em redes permite observar que os sujeitos estão envolvidos de diferentes formas nessa rede, exercendo diferentes formas de poder. Ao falar sobre as formas de governança em rede e as atividades do Estado, Ball (2014, p. 31) destaca: "O movimento para utilizar formas de governança em rede, em algumas áreas de atividade do Estado, pode implicar a perda de poder em algumas partes do Estado, ao mesmo tempo em que há ganhos em outras partes".

Como se observa nas palavras do autor, a organização em rede causa perdas e ganhos de poder pelo Estado. As redes deslocam as hierarquias e mercados, o que corrobora para a ideia de que o Estado atual não é mais o mesmo de cem anos atrás. Nessa nova configuração, as formas de governança não são fixas.

Quanto à lógica empresarial que caracteriza o Estado neoliberal, Dardot e Laval (2016) destacam que não é uma novidade. Segundo os autores, a partir dos anos 1980, espalharam-se por todo o mundo ondas de privatização, desregulamentação e diminuição de impostos. Essas ondas acabaram gerando a noção de desengajamento do Estado, liberando a atuação de capitais privados para campos até então regidos pela lógica não mercantil. Para os autores, a economia de mercado que passa a interferir no estado não funciona sem a rede dos dispositivos sociais.

É importante ressaltar que, mesmo com essa atuação de capitais privados, o Estado não desaparece, mas passa por um processo de reestruturação de fora (privatizações maciças de empresas públicas) e de dentro (novos instrumentos de poder e relações entre governo e sujeitos sociais). Essa reestruturação faz com que o Estado se curve perante às empresas privadas, originando novas práticas de governo, fruto das mutações empresariais. O Estado configura-se em um Estado-empresa, com controle rigoroso e regido pela concorrência. É nessas condições que o Estado é obrigado a funcionar a partir da lógica empresarial, sendo que esse novo modelo cultua a empresa e o empreendedor. A governança difunde as ideias de que a gestão privada é sempre mais eficaz que a pública e as funções públicas passam a ser reguladas a partir do gerencialismo.

Além do Estado em rede e da lógica empresarial, outra característica do Estado em tempos neoliberais é a destituição das instituições disciplinares. Entendendo o Estado atual como fluído, Lewkowicz (2010) afirma que ele já não comporta mais, da mesma forma, a família, a escola, a pedagogia, a maternidade, entre outras. Para o autor, o esgotamento do Estado-nação leva ao esgotamento ou modificação dessas instituições.

A última característica do Estado em tempos neoliberais refere-se à separação entre Estado e Nação ${ }^{2}$. Ao pensar o Estado em tempos modernos, Lewkowicz (2010) destaca que os cidadãos eram definidos perante a lei, transitando entre as diferentes instituições disciplinares. Para o autor, na sociedade moderna, o cidadão precisava ser educado, sendo que a educação contava com a consciência nacional. Mas o que define essa consciência nacional? Após se fazer essa pergunta, o autor conclui: "la institución propia de los Estados nacionales para definir ese ser en conjunto que es el pueblo es la historia. La historia es una institución del siglo XIX que establece que un pueblo es tal porque tiene un pasado en común" (LEWKOWICZ, 2010, p. 21).

2 É importante salientar que as características do Estado em tempos neoliberais aqui apresentadas não são as únicas. As escolhas feitas neste trabalho referem-se ao objetivo central e ao referencial teórico utilizado. Dessa forma, outras abordagens podem trazer outras características. 
Educação em Tempos Neoliberais: ferramentas para leitura da concepção de Educação Superior do Banco Mundial (Relatório de Novembro de 2017)

Para Lewkowicz (2010), o que definiria um Estado-Nação é a ideia de um passado comum entre os povos, constituída através da narrativa histórica institucional. Dessa forma, a fixação desse passado comum é o que define a existência de um presente comum. Aprofundando essa questão, o autor ressalta como a história cria os laços nacionais entre os sujeitos, uma vez que sua narrativa procura em eventos passados construir significados para o presente. Na perspectiva adotada por Lewkowicz (2010), o laço nacional resulta das práticas discursivas em determinadas situações. No entanto, além dos laços entre os cidadãos, o Estado-nação necessita de uma memória institucional. Para o autor, essa memória se dá a partir da construção de uma ideia de identidade nacional, que se utiliza das festas pátrias, dos bens materiais (museus, monumentos, praças, estátuas, etc.), da narrativa histórica, do ensino dessa narrativa histórica nas escolas, entre outros elementos.

De acordo com Bauman e Bordoni (2016), a ideia de Nação está associada a um sentimento de pertencimento, enquanto a de Estado refere-se à noção de território, de espaço físico. Para eles, até os anos 1970, Estado e Nação andavam juntos, no entanto, algo começa a acontecer e modificar essa associação. Os autores destacam que a abertura das fronteiras para o estrangeiro gera, dentre outras coisas, o desagregamento da unidade territorial, causando a separação entre Estado e Nação. Para os autores, além da separação entre esses dois elementos, outro elemento preocupante é a separação entre as noções de poder e política. Considerando essas duas separações (Estado e Nação; poder e política), o mercado passa a exercer poder supranacional, não necessitando mais do Estado, mas de tecnologias e do rompimento das fronteiras. Tentando caracterizar esse novo contexto, Bauman e Bordoni (2016, p. 53) afirmam:

o presente estado do jogo promove competição encarniçada, egoísmo, divisões sociais e desigualdade com o mesmo vigor e a mesma lógica inatacável com que a condição de 'dependência recíproca' gerou limitações à desigualdade social, fortalecimento de compromissos, alianças sólidas e duradouras, e, em resumo, solidariedade humana.

Esse cenário no qual o poder e a política, assim como o Estado e a Nação encontram-se separados, faz com que parte dos poderes do Estado sejam expropriados, passando para o mercado. Podemos pensar a análise do Relatório do Banco Mundial sobre o ensino superior dentro dessa lógica, passando os poderes do Estado (ensino público) para o mercado (instituições privadas). Como destaquei anteriormente, embora o Estado não desapareça, acaba curvando-se ao mercado.

Ainda conforme Bauman e Bordoni (2016), esse contexto atual, ao qual chamam de Pós-modernidade, pode ser caracterizado por um Estado que dirige e controla sem ser responsável. A organização do Estado em rede, a lógica empresarial, a destituição das instituições disciplinares, a separação do Estado e da Nação e das noções de poder e política permitem emergir um novo sujeito. 0 sujeito da pós-modernidade é cada vez mais deixado a sua própria iniciativa (lógica empresarial), sem coesão com os outros sujeitos (separação Estado e Nação), tornando-se um indivíduo sem vínculos sociais.

\section{O SUJEITO NEOLIBERAL}

Esse sujeito característico da pós-modernidade pode ser entendido dentro da lógica do neoliberalismo, configurando-se em um sujeito neoliberal. Uma das suas principais características é a individualização, a fragmentação, que o transforma cada vez mais em indivíduo. Ao analisar o fenômeno da Individualidade, Bauman e Bordoni (2016, p.68) afirmam:

o fenômeno da 'individualidade', outrora visto com contrariedade e desconfiança, com uma mistura de menosprezo e medo, e, feitas as contas, tratada com suspeição, como ameaça à ordem das coisas, tem hoje novo lar na família dos recursos mais desejáveis e das mais louváveis e invejáveis qualidades. Na economia e no Estado, assim como na política da vida, no cenário líquido moderno, a individualidade substitui a ordem, e a individualização demite a ordenação da agenda dos objetivos mais elevados e da lista dos interesses supremos. 
As palavras dos autores demonstram como a lógica da individualidade passa a permear tanto a política de Estado quanto da vida. Essa individualização dos sujeitos em indivíduos torna a sociedade cada vez mais fragmentada, tornando-a líquida. No entanto, além da individualização dos sujeitos, outros elementos constituem o sujeito neoliberal.

De acordo com Dardot e Laval (2016), o sujeito neoliberal deve ser pensado dentro da concepção que entende a sociedade como empresa constituída de empresas, que se difere das sociedades industriais. Essa concepção de sociedade possui uma nova norma subjetiva que, através de novas práticas discursivas e institucionais compõem a figura do sujeito neoliberal, o homem-empresa. Para os autores, "a mercantilização das relações sociais, juntamente com a urbanização, foi um dos fatores mais poderosos da 'emancipação' do indivíduo com relação à tradição, raízes, apegos familiares e fidelidades pessoais" (DARDOT, LAVAL, 2016, p. 323). Como podemos observar, a mercantilização das relações sociais levou ao rompimento do indivíduo com diferentes esferas que o compunham, como a tradição, as raízes, apegos familiares, entre outros.

Essa mesma mercantilização é responsável por uma nova forma de relação social, a contratualização. Retomando, Foucault, Dardot e Laval (2016, p. 325) destacam que, nessa nova forma de relação, passamos a viver em um contexto de gestão das mentes, na qual "[...] o novo governo dos homens penetra até em seu pensamento, acompanha, orienta, estimula, educa esse pensamento". Além das relações de contratualização e do governo das mentes, o neosujeito é caracterizado pelo discurso do sujeito-empresa. Esse novo sujeito deve ser ativo, engajar-se plenamente nas atividades profissionais, ser governado pelos prazeres, produzir cada vez mais felicidade, ser útil, dócil e disposto ao consumo. Nessa lógica, o funcionário passa a ser compreendido como colaborador da empresa.

Segundo Dardot e Laval (2016), a racionalidade neoliberal produz o sujeito que necessita. Os sujeitos se tornam empresas de si, sendo o trabalho transformado em mercadoria, os direitos ligados ao trabalhador corroídos e o medo social torna-se um facilitador da neogestão das empresas, produzindo sujeitos empreendedores. 0 sujeito neoliberal torna-se empreendedor de si mesmo, especialista de si mesmo, competidor. A disciplina torna-se economia pessoal.

A governamentabilidade empresarial passa a ser parte da racionalidade do sujeito neoliberal, transformando a empresa em modelo de trabalhador e modelo de aluno, refletindo no constante trabaIho de si sobre si. Essa nova racionalidade, a partir da governamentabilidade empresarial, transforma os sujeitos em empresas, cujo serviço é a mercadoria vendida. Sendo os sujeitos transformados em empresas, suas vidas passam a ser geridas a partir da lógica empresarial. 0 indivíduo passa a trabalhar para tornar-se mais competitivo e produtivo, querendo atingir o primeiro lugar. Para Dardot e Laval (2016), essa gestão de si torna-se um objeto de comércio intenso.

Para encerrar essa delimitação geral do sujeito neoliberal, é importante destacar ainda os diagnósticos clínicos apresentados por Dardot e Laval (2016), que apontam para o sofrimento no trabalho e a autonomia contrariada, a corrosão da personalidade, a desmoralização, depressão generalizada, a dessimbolização e a 'perversão comum'.

\section{EDUCAÇÃO EM TEMPOS NEOLIBERAIS}

A atuação do neoliberalismo na transformação do Estado em Estado Neoliberal e do sujeito em neosujeito se dá através de diferentes esferas, dentre elas, a educativa. Stephen Ball (2014) destaca que, com o enfraquecimento do Estado-nação, as políticas educativas deixem de estar centradas no Estado, que, por sua vez, perde o poder de controle sobre o sistema de ensino. Considerando que o neoliberalismo 
Educação em Tempos Neoliberais: ferramentas para leitura da concepção de Educação Superior do Banco Mundial (Relatório de Novembro de 2017)

tem, dentre outras consequências, a desnacionalização do Estado e a atuação da lógica empresarial, Ball (2014) aponta que os problemas da educação pública têm, cada vez mais, recebido soluções de cunho do privado. Esse processo de privatização de diferentes setores educativos permite que cada vez mais as empresas interfiram na educação como um todo. Esse parece ser um dos objetivos do diagnóstico apresentado pelo Relatório do Banco Mundial.

Como tenho destacado ao longo do texto, a lógica das empresas comanda o Estado, fazendo com que ele exerça o poder de forma cada vez mais indireta. Essa mesma lógica empresarial penetra de diferentes formas na escola. De acordo com Dardot e Laval (2016, p. 283), "as grandes instituições internacionais, criadas após a Segunda Guerra Mundial (FMI, Banco Mundial, Gatt), constituíram os principais vetores de imposição da nova norma neoliberal" e, como diversos autores têm demonstrado, essa nova norma neoliberal é imposta por algumas dessas instituições por meio da educação e da escola. Considerando que o Banco Mundial está dentro do rol dessas instituições, podemos compreender melhor o que pauta o Relatório aqui em análise.

Lewkowicz (2010) afirma que o esgotamento do Estado-nação acarretou no esgotamento das instituições reguladoras, transformando-as em fragmentos. Dentre essas instituições, pode-se destacar a escola. Assim como as outras instituições, a escola da pós-modernidade não é mais a mesma da modernidade, possuindo novas tarefas, valores e sentidos. Como a lógica neoliberal tem atravessado a educação? Como a concepção de cidadão empreendedor tem estado presente na escola? Como as escolas estão perante o processo de privatização?

Diversos autores têm analisado o problema da educação contemporânea. Partindo de diferentes referenciais ou matrizes teóricas, esses autores apresentam variadas formas de compreender o fenômeno educativo em tempos de neoliberalismo. Apresento a partir de agora alguns desses autores, mostrando as diferentes ferramentas utilizadas para compreender as modificações na educação e na escola. Meu objetivo em apresentar esses diferentes estudos é que, a partir deles, o leitor possa ampliar seu olhar sobre o fenômeno que articula educação e neoliberalismo e, consequentemente, ampliar seu espectro de leitura para o Relatório do Banco Mundial em análise.

\section{CURRÍCULO, TEMPO E ESPAÇO: INDIVIDUALISMO E TRANSITORIEDADE}

A partir do currículo, Alfredo Veiga-Neto já atentava, em 2002, para as modificações do universo escolar. Para o autor, o currículo é o responsável por promover a abstração das noções de tempo e espaço, tendo se tornado, durante a modernidade, o eixo central da escola. Para ele, o currículo geometriza os saberes e o mundo. Essa geometrização a partir do currículo faz com que Veiga-Neto (2002) o entenda como a principal máquina de fabricação da modernidade, rompendo com a concepção de tempo e espaço medieval. Ao geometrizar a distribuição e hierarquização dos saberes, o currículo estabeleceu o fundo para que o mundo seja entendido de forma geométrica.

Considerando a atuação do currículo na passagem da Idade Média para a modernidade, como ele atuaria perante a crise dessa última? Como o currículo poderá responder às mudanças das últimas duas ou três décadas? Para o autor, o currículo deve ser pensado em relação com as novas configurações sociais, econômicas, políticas e culturais. Preocupado em "descrever, examinar e problematizar as relações entre o currículo e a ressignificação do espaço e do tempo" (VEIGA-NETO, 2002, p. 167) na pós-modernidade, $\mathrm{o}$ autor destaca que o mundo contemporâneo está vivenciando outra ruptura radical nas formas de significação tempo/espaço. 
Veiga-Neto (2002) destaca ainda que o mundo está mudando, passando a ser uma arma na conquista do espaço; que a velocidade está ligada à ideia de dominação; que existem novas concepções de fronteira, de tempo e de espaço. A sociedade está cada vez mais marcada pela volatilidade, uma vez que vivemos em um estado de contínua mudança, de sensação de instabilidade. Os sujeitos passam a viver cada vez mais a curto prazo, com tudo mudando rapidamente. Tenta-se estar presente em todos os lugares, principalmente a partir da tela do computador. Para o autor, o diferencial da volatilidade estabelece um diferencial de poder, em que os mais capazes de se moverem rapidamente podem dominar facilmente os menos voláteis.

Agora a geometria é outra. Segundo Veiga-Neto (2002), existem várias conexões entre o caráter transitório das identidades culturais e a reorganização curricular. A primeira conexão apresentada por ele refere-se à flexibilização do currículo, na qual o aluno pode escolher o que irá cursar. Para o autor, essa flexibilização está diretamente ligada a uma relação cliente e produto. Uma segunda conexão apresentada refere-se à transformação do espaço escolar em um não lugar, o que está ligado à prática de cada um poder escolher seu próprio currículo. Essa flexibilização do currículo e a transformação da escola em não lugar causam a ausência de uma identidade de turma e de uma história. Os não lugares ensinam o individualismo e naturalizam a transitoriedade que, como anteriormente apresentados, são característicos do sujeito neoliberal.

\section{APRENDIZAGEM AO LONGO DA VIDA}

Licínio Lima (2010) problematiza a ideia de aprendizagem ao longo da vida, tensionando o questionamento "A Educação faz tudo?". Utilizando-se de conceitos freirianos, o autor mostra uma mudança paradigmática do conceito de educação para aprendizagem. Para Lima (2010), o conceito de aprendizagem é incorporado pelo sistema neoliberal, colocando-o dentro de uma indústria de serviços.

Estando a educação a serviço do mercado, pode-se observar uma mudança nas relações entre alunos e professores, na qual os alunos passam a ser entendidos como clientes ou consumidores. Entendendo a educação a partir desse processo de capitalização, o autor afirma que as multinacionais têm dominado o setor educativo, transformando a aprendizagem em uma empresa, na qual cada vez utilizam-se menos professores e mais outros profissionais, que são considerados qualificados justamente por não serem professores.

Retomando Stephen Ball (2000), Lima (2010, p. 42) mostra como a aprendizagem tem sido utilizada como tentativa de solução para a crise econômica e social. Dessa forma, emerge o conceito de 'aprendizagem ao longo da vida', tido, muitas vezes, quase como que "um medicamento administrativo para tratar os males de que tantos pacientes sofrem". A formação ao longo da vida é pautada pela ideia de empregabilidade, mistificando e exaltando a lógica de responsabilidade individual, levando o indivíduo a se tornar empresário de si.

O empresariamento de si e a aprendizagem ao longo da vida ganham rigor nos discursos políticos, em congruência, o conceito de educação vai sendo progressivamente substituído pelo conceito de aprendizagem ao longo da vida e por seus derivados (qualificações, competências e habilidades), termos funcionais e adaptativos. Como demonstrei ao longo deste trabalho, o empresariamento de si e a compreensão dos indivíduos como empresas são traços marcantes do neoliberalismo e do sujeito neoliberal, percebidos também na lógica educacional. 
Educação em Tempos Neoliberais: ferramentas para leitura da concepção de Educação Superior do Banco Mundial (Relatório de Novembro de 2017)

\section{DISPOSITIVO DE APRENDIZAGEM}

Simons e Masschelein (2013) defendem a ideia de que o poder disciplinar e o panóptico já não são mais suficientes para pensarem a educação na contemporaneidade. Para eles, o conceito de dispositivo de aprendizagem seria mais potente e coerente. Entendendo a aprendizagem como problema/solução, os autores distinguem quatro campos de problemas relacionados: 1. Capitalização da aprendizagem; 2. Ser responsável pela aprendizagem; 3 . Aprendizagem como objeto de (auto) gestão e (auto) especialização; 4. Empregabilidade dos resultados de aprendizagem.

Embora em uma abordagem teórica diferente de Lima (2010), pode-se propor algumas aproximações entre os autores. No caso da capitalização da aprendizagem, Simons e Masschelein (2013) afirmam que a aprendizagem é considerada uma condição para o desenvolvimento econômico e a produtividade. Essa condição gera um processo de capitalização da aprendizagem, vendo-a como uma forma de produção do valor. Esse processo é muito próximo da capitalização da aprendizagem proposta por Lima (2010), na qual o mercado causa profundas mudanças no sistema educativo.

Assim como na aproximação anterior, o segundo ponto de Simons e Masschelein (2013), o "ser responsável pela aprendizagem" pode ser pensado em paralelo com a responsabilização individual que Lima (2010) aborda como propulsora do empresariamento de si. Ao mesmo tempo, a aprendizagem como objeto de (auto) gestão e (auto) especialização dos autores pode ser relacionada com a ideia de responsabilização do sujeito, apresentada por Lima (2010). Além disso, a empregabilidade dos resultados de aprendizagem de Simon e Masschelein (2013) pode ser pensada em relação à 'aprendizagem ao longo da vida" de Lima (2010), que é pautada pela ideia de empregabilidade, sendo em alguns momentos, vista quase como um remédio para os males sociais econômicos.

\section{ALGUNS APONTAMENTOS}

Defendi, ao longo do texto, que o neoliberalismo pode ser compreendido como uma forma de mutação do capitalismo que converte o trabalhador em empresário de si, não sendo apenas um modo econômico, mas uma forma de viver a vida que fabrica seus próprios sujeitos. Esse sujeito neoliberal é marcado, dentre outras coisas, pela individualização e pelo empreendimento de si. Além de interferir diretamente nos sujeitos, o neoliberalismo interfere também na lógica de constituição do Estado. Em tempos neoliberais, o Estado passa não mais a estar configurado de forma hierárquica, mas em redes, nas quais os sujeitos exercem poder de diferente intensidade, de acordo com o local que ocupam. Além da configuração em rede, o Estado neoliberal passa a ser gestado a partir da lógica empresarial (privatização), as instituições disciplinares começam a desaparecer e observamos a separação entre Estado e Nação.

Ao interferir na constituição do Estado e dos sujeitos, o neoliberalismo passa a estar presente nas mais diversas esferas da vida, dentre elas, a esfera educativa. Apresentei aqui três conceitos para pensarmos a educação em tempos neoliberais: Currículo: Individualismo e Liberdade; Aprendizagem ao Longo da Vida e Dispositivo de Aprendizagem. Como sugeri no início do texto, meu objetivo não era analisar o Relatório do Banco Mundial, mas oferecer algumas ferramentas que auxiliassem na interpretação e leitura a partir do conceito de neoliberalismo.

Iniciei esse trajeto apresentando o conceito de neoliberalismo e a importância de se conhecer o conceito para combater essa configuração do capital, destacando as mutações sofridas pelo Estado e pelos sujeitos, bem como alguns conceitos para pensarmos a educação em tempos neoliberais. Penso que esse percurso ajuda a compreender o relatório do Banco Mundial como parte de uma rede de interesses pautada pelo capital, situada dentro do sistema neoliberal, entendendo os investimentos 
em educação como gastos, transferindo para as empresas privadas o compromisso com a educação e tirando o compromisso do Estado com a formação pública e de qualidade. A proposta do Banco é um movimento contrário ao acesso universal gratuito, colocando em xeque direitos adquiridos e pautando a formação superior na lógica puramente mercadológica.

\section{REFERÊNCIAS}

BALL, S. J. Educação Global S.A. Novas redes políticas e o imaginário neoliberal. Editora UEPG, 2014.

BAUMAN, Z.; BORDONI, C. Estado de Crise. Rio de Janeiro: Zahar, 2016.

DARDOT, P.; LAVAL, C. A Nova Razão do Mundo: ensaios sobre a sociedade Neoliberal, 2016.

LAVAL; DARDOT. El neoliberalismo es una forma de vida, no sólo una ideología o una política económica. In: Interferencias. Disponível. em: http://www.eldiario.es/interferencias/neoliberalismo-ideologia-politicaeconomica-forma_6_312228808.html. Acesso em: 23 set. 2020.

LEWKOWICZ, I. Escuela y Cidadanía. In: COREA, Cristina; LEWKOWICZ, I. Pedagogía del Aburrido: Escuelas destituidas, familias perplejas. Buenos Aires: Paidós, 2010.

LIMA, L. A Educação faz tudo? Crítica ao Pedagogismo na 'sociedade da aprendizagem'. Revista Lusófona de Educação, v. 15, p. 41-54, 2010.

RELATÓRIO DO BANCO MUNDIAL. Um Ajuste Justo. Análise da Eficiência e Equidade do Gasto Público no Brasil. Novembro de 2017.

SIMONS, M.; MASSCHELEIN, J. Se nos hace creer que se trata de nuestra libertad: notas sobre la irinia del dispositivo de aprendizaje. Pedagogia y Saberes, $n^{\circ} 38$, Universidad Pedagógica Nacional, Facultad de Educación, p. 93-102, 2013.

VEIGA-NETO, A. De geometrias, currículo e diferenças. Educação \& Sociedade, ano XXIII, n 79, agosto/ 2002. 